\title{
Alterações morfológicas induzidas por butirato, propionato e lactato sobre a mucosa ruminal e epiderme de bezerros. II. Aspectos ultra-estruturais
}

\author{
[Lactate, propionate, and butyrate induced morphological alterations on calf ruminal \\ mucosa and epidermis. II. Ultra-structurals aspects] \\ S.F. Costa ${ }^{1}$, M.N. Pereira ${ }^{1}$, L.Q. Melo ${ }^{1}$, M.V. Caliari $^{2}$, M.L. Chaves ${ }^{1}$ \\ ${ }^{1}$ Universidade Federal de Lavras \\ Caixa Postal 3037 \\ 37200-000 - Lavras, MG. \\ ${ }^{2}$ Universidade Federal de Minas Gerais - Belo Horizonte, MG.
}

\begin{abstract}
RESUMO
Avaliou-se o efeito de ácidos graxos voláteis (AGV) sobre a integridade do epitélio no rúmen, no plano nasolabial, na epicera e no perioplum traseiro e dianteiro de bezerros e validou-se a feitura de biópsias tegumentares como indicadores de alterações morfológicas da mucosa ruminal. Dezessete bezerros, com sonda no rúmen, receberam infusões intra-ruminais de AGV ou salina, durante 37 dias. Aos 89 dias de vida, após o abate, foram colhidas amostras dos tecidos. Os AGV aumentaram a área de epitélio total e a área de células metabolicamente ativas no epitélio ruminal, embora o butirato não tenha induzido ao desenvolvimento papilar. A área de epitélio não queratinizado no plano nasolabial foi reduzida pela infusão de AGV. Butirato e lactato foram mais indutores de alterações patológicas no epitélio ruminal. Não foram observadas lesões histológicas nos epitélios do plano nasolabial, da epicera e do perioplum, mostrando que essas são conseqüências do efeito direto dos AGV sobre o epitélio ruminal. Os efeitos indireto e direto dos AGV sobre a morfologia dos tecidos epiteliais queratinizados não foram iguais. Biópsias tegumentares podem ter utilidade como indicadores de alterações morfológicas da mucosa ruminal.
\end{abstract}

Palavras-chave: bezerro, ácidos graxos voláteis, plano nosolabial, epicera, perioplum

\begin{abstract}
The effect of volatile fatty acids (VFA) on rumen wall, epidermis of nasolabial surface, perioplum, and epicera of calves was evaluated. The experiment also aimed to validate the procedure of tegument biopsies as indicators of ruminal mucosa alterations. Seventeen neonatal calves with foley catheters received intraruminal infusions of VFA or saline, during 37 days. At 89-day-old, the animals were slaughtered and tissue samples were collected from rumen, nasolabial surface, epicera, and perioplum from face and hindquarters. VFA infusion increased total epithelium area and metabolically active ruminal cell area; although butirate did not induce the papilar development. The effect of nasolabial surface VFA infusion was the opposite to that observed in the rumen. No histological lesion was observed on nasolabial surface, epicera, and perioplum, demonstrating that these are consequences of VFA direct effect on ruminal epithelium. Butyrate and lactate induced more alterations on the ruminal epithelium. Indirect and direct VFA effects on keratinized epithelium tissues morphology were not identical. Tegumentary biopsies may be useful as indicators of morphological alterations of ruminal mucosa.
\end{abstract}

Keywords: calf, volatile fatty acids, nasolabial surface, epicera, perioplum

Recebido em 3 de maio de 2007

Aceito em 11 de fevereiro de 2008

E-mail: sfcosta@ufla.br 


\section{INTRODUÇÃO}

Alta taxa de produção e absorção de ácidos graxos voláteis (AGV) no rúmen é requerida para o suprimento de nutrientes necessários para o desempenho satisfatório de ruminantes. No entanto, a ingestão de dietas ricas em carboidratos rapidamente fermentáveis no rúmen pode resultar em acúmulo excessivo de AGV no fluido ruminal, desencadeando um quadro de acidose (Barker et al., 1995). A acidose ruminal pode afetar negativamente o desempenho e a saúde animal (Bernardes et al., 2007) mediante efeitos deletérios sobre a motilidade do rúmen (Crichlow e Chaplin, 1985), a fermentação da fibra (Krajcarski-Hunt et al., 2002), o consumo de alimentos (Krajcarski-Hunt et al., 2002) e a morfologia da parede ruminal (Ahrens, 1967).

Propionato e butirato parecem ser mais estimuladores do crescimento papilar que o acetato (Vair et al., 1960). No entanto, o efeito direto do butirato sobre o epitélio ruminal parece ser inibidor de mitose e indutor de diferenciação celular (Staiano-Coico et al., 1990), o que é indesejável do ponto de vista de integridade e atividade metabólica da parede ruminal. O propionato parece ser o AGV responsável pelo crescimento de papilas metabolicamente ativas.

O acúmulo ruminal de lactato pode ocorrer por indução experimental de acidose aguda em ruminantes (Crichlow e Chaplin, 1988; Crichlow, 1988). No entanto, vacas leiteiras que receberam dietas de alto conteúdo energético apresentaram concentrações plasmáticas de Dlactato muito abaixo das observadas nesses experimentos (Pereira et al., 1999). O papel do lactato e de outros AGV na etiopatogenia da acidose em vacas leiteiras precisa ser melhor esclarecido a fim de que medidas de controle tecnicamente fundamentadas sejam adotadas para o controle desse distúrbio metabólico.

Alterações microscópicas no processo de queratinização observadas em bovinos com distúrbios nos membros locomotores (Singh et al., 1992) podem atuar como fator predisponente ao aparecimento de afecções de casco, por alterar suas morfologia e dureza (Hendry et al., 1999). A indução de acidose em eqüinos afeta tanto a queratinização dos cascos quanto das castanhas, sugerindo que a patologia pode ter natureza sistêmica. Apesar de a extração de butirato e propionato pelo fígado ser alta (Krehbiel et al., 1992), o teor plasmático desses AGV aumenta após a alimentação em ovinos (Ross e Kitts, 1973). Danos morfológicos no tecido epitelial do rúmen e de cascos podem ter os AGV como causa comum, possivelmente explicando a ocorrência simultânea de anomalias no rúmen e nos cascos de bovinos sujeitos à acidose ruminal.

O objetivo deste trabalho foi avaliar o efeito de butirato, do propionato e do lactato sobre a integridade de tecidos epiteliais estratificados queratinizados de bezerros e validar a feitura de biópsias tegumentares como indicadores de alterações morfológicas da mucosa ruminal.

\section{MATERIAL E MÉTODOS}

Aos 45 dias de vida, 17 bezerros da raça Holandesa foram submetidos à implantação cirúrgica de sonda de gastrostomia humana ${ }^{1}$ no rúmen. Aos 52 dias de idade, os animais foram aleatoriamente alocados em um dos quatro tratamentos: infusões intra-ruminal de butirato (B), lactato (L), propionato $(\mathrm{P})$ ou salina $(\mathrm{S})$, este último usado como tratamento-controle, por 37 dias. Detalhes de local, manejo alimentar, infusão $\mathrm{AGV}$, coleta e processamento histológico de amostras foram relatados em Costa et al. (2008).

Para mensurações das áreas de epitélio total e de queratina nas regiões do saco cranial, recesso e saco cego caudoventral do rúmen e no plano nasolabial, os cortes foram corados com Tricrômico de Masson (Luna, 1968) e mensurados com o software KS300 contido em um analisador de imagens ${ }^{2}$, de acordo com Caliari (1997)

A avaliação histológica constou de um exame de todo o corte histológico presente na lâmina de cada animal por tratamento, de acordo com Coelho (1999), com algumas modificações. Foi utilizada a seguinte classificação: epitélio normal, desproporção entre as camadas com formação de vacúolos (lesão leve), desproporção entre as camadas com formação de vacúolos e

${ }^{1}$ Ross Flexiflo 20 French, Abbot Laboratórios do Brasil Ltda. - São Paulo, Brasil.

${ }^{2}$ Kontron Elektronic/Carl Zeiss, Carl Zeiss do Brasil - São Paulo, Brasil. 
infiltrado inflamatório polimorfonuclear (lesão moderada), desproporção entre as camadas com intensa formação de vacúolos e infiltrado inflamatório polimorfonuclear (lesão grave), desproporção entre as camadas com intensa formação de vacúolos, infiltrado inflamatório polimorfonuclear e áreas de erosão (lesão muito grave). As alterações histológicas no epitélio ruminal foram avaliadas apenas quanto à porcentagem de alterações por tratamento.

Amostras independentes da parede do recesso e saco-cego caudoventral do rúmen foram obtidas para avaliar características ultra-estruturais do epitélio em microscopia eletrônica de transmissão. $\mathrm{O}$ material foi processado de acordo com Camargos e Neto (1995). Para estudo ultra-estrutural e obtenção de micrografias eletrônicas, utilizou-se o microscópio eletrônico de transmissão ${ }^{3}$.

Os dados morfométricos foram analisados pelo procedimento GLM do pacote estatístico SAS (User's..., 1985). Foram testados três contrastes ortogonais com um grau de liberdade: butirato versus salina, lactato versus salina e propionato versus salina.

\section{RESULTADOS E DISCUSSÃO}

Aspectos deste experimento relacionados às dimensões papilares, índice mitótico (IM) e insulina sorológica foram publicados em Costa et al. (2008). Os AGV aumentaram a área de epitélio total e a área de células metabolicamente ativas no epitélio ruminal (Tab. 1). Esses dados não são coerentes com os dados de tamanho papilar (Costa et al., 2008), pois sugerem que todos os $\mathrm{AGV}$ foram igualmente capazes de induzir crescimento de tecido epitelial metabolicamente ativo. Essa incoerência nos resultados pode ser explicada pelo fato de $\mathrm{o}$ butirato ter induzido $\mathrm{o}$ crescimento epitelial sem, no entanto, induzir o desenvolvimento de papilas. A mensuração morfométrica da área de epitélio foi executada em toda a superfície epitelial presente nos cortes histológicos e não apenas no epitélio papilar. Os fatores reguladores da formação das papilas ruminais podem não atuar de maneira idêntica aos fatores determinantes do crescimento

${ }^{3}$ EM.10 Zeiss, Carl Zeiss do Brasil - São Paulo, Brasil. epitelial. Bovinos que receberam concentrados e com alta capacidade ruminal de absorção de AGV (Perrier et al., 1994) podem apresentar hiperqueratose e atrofia papilar (McGavin e Morrill, 1976).

No tratamento $B$, o epitélio ruminal foi mensurado apenas nas regiões do corte histológico onde o epitélio não tinha erosão (Tab. 1 e Fig.1). Nos tratamentos $\mathrm{P}$ e $\mathrm{S}$, as mensurações foram executáveis em todos os segmentos de epitélio, pois todas as áreas tinham epitélio íntegro. Os dados do tratamento $\mathrm{L}$ devem ser interpretados com cautela, pois, em todas as regiões de todos os cortes histológicos, o epitélio tinha degeneração hidrópica e apresentava o contorno epitelial definido, tornando-o apto a ser mensurado. Apesar da resposta positiva em crescimento de células metabolicamente ativas à infusão de lactato, o epitélio foi completamente danificado por esse AGV (Tab. 2 a 4), e grande parte da área epitelial era composta por vacúolos e células vacuolizadas (Fig. 1). Degenerações hidrópicas foram relatadas em novilhas sujeitas à indução experimental de acidose lática e após infusão intra-ruminal de lactato (Ahrens, 1967). Lesões histológicas não foram observadas nos cortes dos epitélios do plano nasolabial, da epicera e do perioplum, mostrando que essas são conseqüências do efeito direto dos $\mathrm{AGV}$ sobre o epitélio ruminal.

O lactato reduziu a queratinização do epitélio ruminal, em conseqüência tanto da pequena área de tecido queratinizado, quanto do aumento na área total de epitélio, devido à vacuolização das células epiteliais (Tab. 1 e Fig. 1). Butirato resultou em queratinização similar a propionato. Esse achado não era esperado, já que butirato é sabidamente estimulador de diferenciação celular em epitélios estratificados (StaianoCoico et al., 1990; Gálfi et al., 1993). No entanto, nos cortes histológicos dos animais que receberam butirato, foram freqüentemente observadas camadas de queratina desprendidas do epitélio, e essas não foram incluídas nas mensurações de área.

A hiperqueratose é reconhecidamente uma conseqüência de dietas ricas em concentrados (Jensen et al., 1954), e esse achado é freqüentemente associado à perda in vivo da camada de queratina (Tamate e Kikuchi, 1978). 
Tabela 1. Áreas de epitélio total, queratina e diferença entre área de epitélio total e área de queratina nos epitélios do rúmen e plano nasolabial de bezerros mantidos em dieta exclusivamente líquida e recebendo infusões intra-ruminais de butirato, lactato, propionato ou salina

\begin{tabular}{|c|c|c|c|c|c|c|c|c|c|}
\hline & B & $\mathrm{L}$ & $\mathrm{P}$ & $\mathrm{S}$ & EPM & P Trat & $\mathrm{B} v s \mathrm{~S}$ & $\mathrm{~L} v s \mathrm{~S}$ & $\mathrm{P} v s \mathrm{~S}$ \\
\hline \multicolumn{10}{|c|}{ Epitélio total $\left(\mu \mathrm{m}^{2}\right)$} \\
\hline Saco cranial & 214.747 & 219.425 & 268.082 & 146.146 & 20,90 & 0,03 & 0,07 & 0,03 & $<0,01$ \\
\hline Recesso & 150.868 & 123.603 & 162.083 & 76.171 & 13,76 & $<0,01$ & $<0,01$ & 0,03 & 0,001 \\
\hline $\begin{array}{l}\text { Saco cego } \\
\text { caudo-ventral }\end{array}$ & 285.087 & 147.701 & 147.969 & 100.104 & 43,27 & 0,06 & 0,01 & 0,45 & 0,47 \\
\hline Plano nasolabial & 393.540 & 432.272 & 378.498 & 529.170 & 35,51 & 0,06 & 0,02 & 0,08 & 0,01 \\
\hline \multicolumn{10}{|c|}{ Queratina $\left(\mu \mathrm{m}^{2}\right)$} \\
\hline Saco & 13.012 & 4.429 & 22.560 & 7.396 & 4,68 & 0,10 & 0,47 & 0,67 & 0,07 \\
\hline Recesso & 9.589 & 3.713 & 9.293 & 6.793 & 2,10 & 0,21 & 0,39 & 0,32 & 0,44 \\
\hline $\begin{array}{l}\text { Saco cego } \\
\text { caudo-ventral }\end{array}$ & 16.702 & 4.691 & 14.919 & 4.655 & 4,640 & 0,19 & 0,11 & 0,99 & 0,16 \\
\hline Plano nasolabial & 41.748 & 43.801 & 36.628 & 37.514 & 5,10 & 0,72 & 0,59 & 0,40 & 0,90 \\
\hline \multicolumn{10}{|c|}{ Epitélio total - queratina $\left(\mu \mathrm{m}^{2}\right)$} \\
\hline Saco & 201.735 & 214.996 & 245.522 & 138.749 & 21,15 & 0,05 & 0,09 & 0,03 & 0,01 \\
\hline Recesso & 141.280 & 119.889 & 152.790 & 69.377 & 13,96 & $<0,01$ & $<0,01$ & 0,02 & 0,001 \\
\hline $\begin{array}{l}\text { Saco cego } \\
\text { caudo-ventral }\end{array}$ & 268 & 14 & 13 & 0 & 41 & 0,07 & 0,01 & 0,43 & 0,55 \\
\hline Plano nasolabial & 351.792 & 388.470 & 362.952 & 491.655 & 36,48 & 0,08 & 0,02 & 0,07 & 0,03 \\
\hline
\end{tabular}

$\mathrm{EPM}=$ erro-padrão da média. $\mathrm{P}$ trat=probabilidade para efeito de tratamento. $\mathrm{B} v s \mathrm{~S}, \mathrm{~L} v s \mathrm{~S}$ e $\mathrm{P} v s \mathrm{~S}=$ probabilidade para os contrastes ortogonais butirato versus salina (B vs S), lactato versus salina ( $\mathrm{L}$ vs $\mathrm{S}$ ) e propionato versus salina (P vs S).

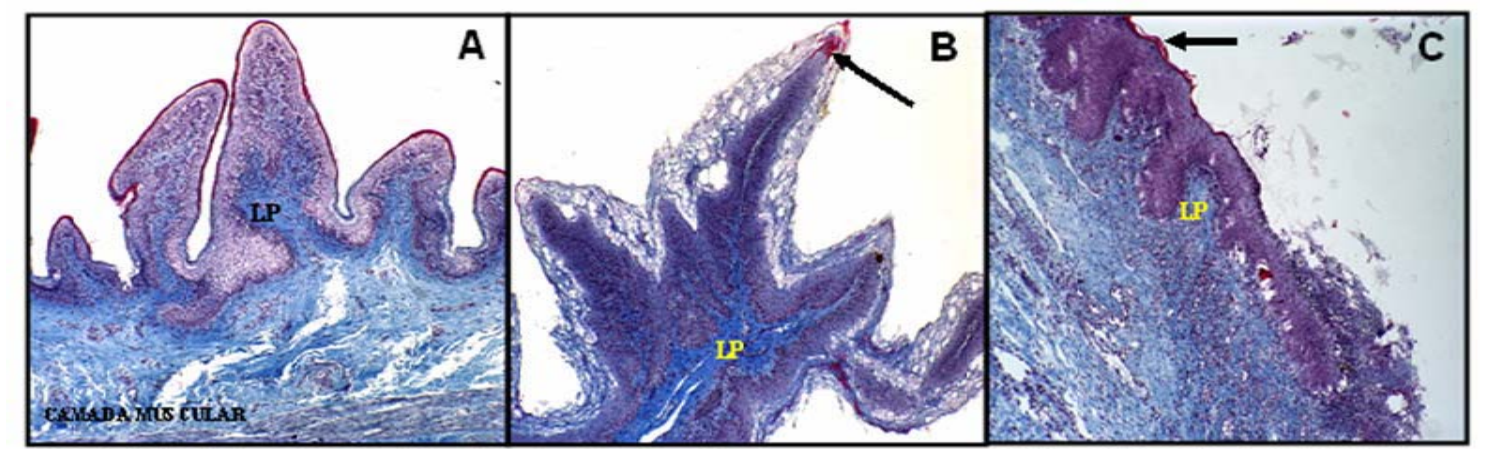

Figura 1. Cortes histológicos longitudinais de mucosa ruminal: A) Saco cranial (salina). B) Recesso (lactato), papila ramificada e com contorno irregular, epitélio vacuolizado com poucas células queratinizadas (seta). C) Saco cego caudoventral (butirato), extensa área de erosão epitelial e fina camada de queratina (seta). Lâmina própria (LP). Camada córnea corada em vermelho. Tricrômico de Masson. 100X

As técnicas histológicas utilizadas podem não ter sido as mais adequadas para quantificar possíveis diferenças de queratinizações do epitélio ruminal em resposta à infusão de butirato no rúmen.

A área de epitélio não-queratinizado no plano nasolabial foi reduzida pela infusão de AGV (Tab. 1). Tanto lactato como butirato reduziram numericamente o IM das células da camada basal da epiderme na região do focinho (Costa et al., 2008). A maior porcentagem de queratina em resposta à infusão de $\mathrm{AGV}$ não resultou do aumento na área de queratina e sim da redução na área de tecido não-queratinizado. $\mathrm{O}$ efeito da infusão de $\mathrm{AGV}$ nesse tecido foi contrário ao efeito observado no rúmen. Não ficou evidente se o efeito indireto dos AGV sobre o epitélio do plano nasolabial poderia ter sido mediado por insulina, já que a maior concentração sorológica de insulina no tratamento B (Costa et al., 2008) não resultou em resposta diferenciada a esse AGV. 
Nos quatro animais infundidos com salina, a mucosa nas diferentes regiões do rúmen estava íntegra e com papilas de contorno regular. A avaliação ultra-estrutural do epitélio ruminal revelou a presença de características relacionadas com a biossíntese de substâncias queratinosas (Fig. 2) similares às descritas na literatura (Dellmann e Brown, 1982).

Nenhuma área avaliada dos epitélios do rúmen de animais que receberam infusões de AGV foi considerada normal, devido à presença de lesões celulares, as quais sugeriram processos degenerativos (Tab. 2 a 4 e Fig. 1). No tratamento $\mathrm{P}$, as lesões foram classificadas como leves ou moderadas. No saco cranial e recesso do rúmen de um dos quatro animais que receberam propionato, foi observada desproporção entre as camadas celulares do epitélio relativamente ao tratamento-controle, sendo o mesmo observado no saco cego caudoventral em três desses animais. As células da camada granulosa apresentaram halos claros perinucleares e citoplasma ligeiramente vacuolizado. O saco cego caudoventral de um animal apresentava lesões moderadas, definidas pela presença de infiltrado inflamatório polimorfonuclear, associado às lesões já descritas. Papilas mais desenvolvidas foram mais ramificadas e com maior proporção de células vacuolizadas (Tab. 2 a 4).

Tabela 2. Avaliações histológicas expressas em porcentagem de ocorrência no saco cranial do rúmen de bezerros mantidos em dieta exclusivamente líquida e que receberam infusões intra-ruminal de butirato, lactato, propionato ou salina

\begin{tabular}{lccccc}
\hline \multirow{2}{*}{ Tratamento } & \multicolumn{5}{c}{ Alteração (\%) } \\
\cline { 2 - 6 } & 1 & 2 & 3 & 4 & 5 \\
\hline Butirato & 0 & 0 & 0 & 100 & 0 \\
Lactato & 0 & 0 & 0 & 100 & 0 \\
Propionato & 0 & 100 & 0 & 0 & 0 \\
Salina & 100 & 0 & 0 & 0 & 0 \\
\hline
\end{tabular}

1= normal, 2 = lesão leve, 3 = lesão moderada, $4=$ lesão grave, $5=$ lesão muito grave.

Tabela 3. Avaliações histológicas expressas em porcentagem de ocorrência no recesso do rúmen de bezerros que foram mantidos em dieta exclusivamente líquida e receberam infusões intra-ruminal de butirato, lactato, propionato ou salina

\begin{tabular}{lccccc}
\hline \multirow{2}{*}{ Tratamento } & \multicolumn{5}{c}{ Alteração (\%) } \\
\cline { 2 - 6 } & 1 & 2 & 3 & 4 & 5 \\
\hline Butirato & 0 & 0 & 0 & 50 & 50 \\
Lactato & 0 & 0 & 0 & 100 & 0 \\
Propionato & 0 & 100 & 0 & 0 & 0 \\
Salina & 100 & 0 & 0 & 0 & 0 \\
\hline
\end{tabular}

1= normal, 2 = lesão leve, 3 = lesão moderada, 4= lesão grave, $5=$ lesão muito grave.

As células basais no epitélio ruminal de animais no tratamento $\mathrm{P}$ apresentaram características ultra-estruturais semelhantes às dos animais do tratamento-controle. Entretanto, foi observada maior quantidade de organelas envolvidas na biossíntese de substâncias queratinosas, sugerindo que o propionato estimulou aumento no metabolismo celular da camada basal. A camada espinhosa apresentou características morfológicas também similares às do tratamento $\mathrm{S}$, porém observou-se maior quantidade de feixes filamentosos espalhados pela célula. Células granulares apresentaram núcleos achatados com características degenerativas e maior quantidade de grânulos de queratohialina que os animais no tratamento S. Ocasionalmente foram observados núcleos contendo cromatina compactada, sugerindo a presença de corpos apoptóticos, sinais morfológicos de morte celular por apoptose. $\mathrm{O}$ aumento da quantidade de feixes filamentosos nas camadas basal e espinhosa e a grande quantidade de grânulos de queratohialina indicam que houve síntese de queratina completa na camada espinhosa e acelerada taxa de 
diferenciação pós-mitótica. A camada córnea apresentou células bem achatadas contendo restos nucleares e material fibrilar. A retenção de núcleo e a presença de rede fibrosa na camada córnea sugerem alterações nas atividades das enzimas lisosômicas (Fig. 3). O propionato aparentemente causou ruminite química branda com síntese precoce de queratina, caracterizando um quadro de disqueratose, hiperqueratose e paraqueratose típica de ruminantes (Tamate e Kikuchi, 1978).

Tabela 4. Avaliações histológicas expressas em porcentagem de ocorrência no saco cego caudoventral do rúmen de bezerros que foram mantidos em dieta exclusivamente líquida e receberam infusões intraruminal de butirato, lactato, propionato ou salina

\begin{tabular}{lccccc}
\hline \multirow{2}{*}{ Tratamento } & \multicolumn{5}{c}{ Alteração (\%) } \\
\cline { 2 - 6 } & 1 & 2 & 3 & 4 & 5 \\
\hline Butirato & 0 & 0 & 0 & 50 & 50 \\
Lactato & 0 & 0 & 0 & 100 & 0 \\
Propionato & 0 & 75 & 25 & 0 & 0 \\
Salina & 100 & 0 & 0 & 0 & 0 \\
\hline
\end{tabular}

1= normal, $2=$ lesão leve, $3=$ lesão moderada, $4=$ lesão grave, $5=$ lesão muito grave.

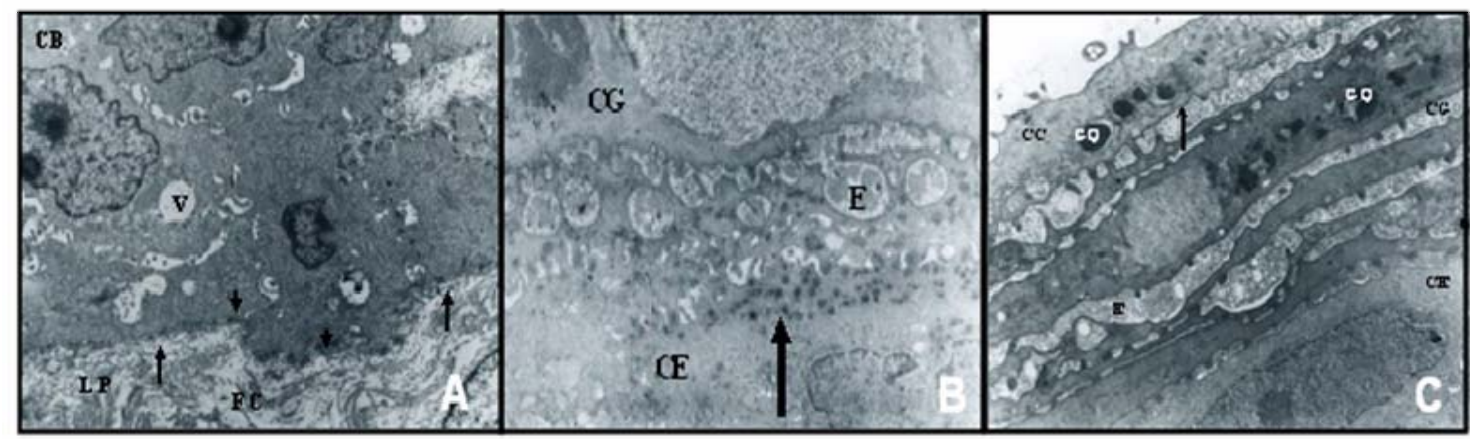

Figura 2. Micrografias eletrônicas do epitélio ruminal (salina): A) Camada basal (CB). Membrana basal ligeiramente tortuosa (setas). Vacúolos (V); Lâmina própria (LP); Fibrilas colágenas (FC). 7.760X. B) Transição da camada espinhosa para camada granular (CG). Grânulos limitados por membrana (seta). Espaço intercelular (E). 7.760X. C) Camadas espinhosa, granular e córnea (CC). Grânulos de queratohialina (GQ). 10.272X

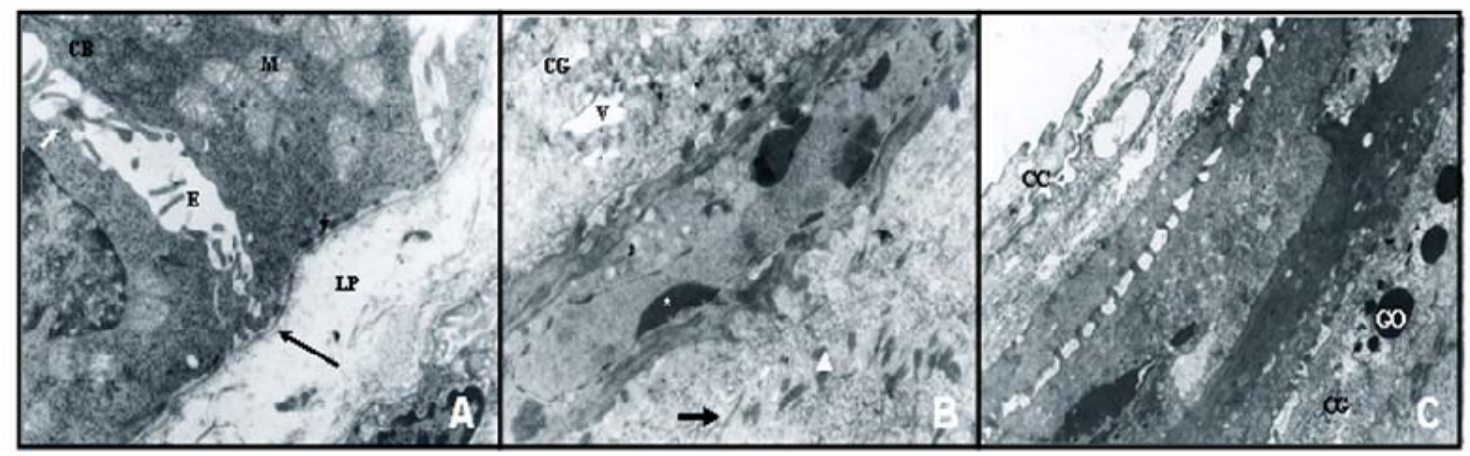

Figura 3. Micrografias eletrônicas do epitélio ruminal (propionato). A) Camada basal (CB). Desmosoma unindo duas células vizinhas (seta branca). Membrana basal íntegra (seta preta) e salpicada por hemidesmosomas (cabeça de seta preta). Mitocôndrias (M), Lâmina própria (LP). 16.032X. B) Camada granular (CG). Núcleo alongado e apresentando massas compactas de heterocromatina $(*)$, sugerindo a presença de corpos apoptóticos. Feixes filamentosos intracitoplasmáticos (seta) e desmosomos (cabeça de seta branca). Vacúolos (V). 12.880X. C) Transição da camada granular para camada córnea (CC). Grânulos de queratohialina (CQ). 7.760X 
Em todos os animais do tratamento L, as alterações ruminais foram consideradas graves (Tab. 2 a 4 e Fig. 1). Foram observadas papilas bem ramificadas e epitélio contendo grandes vacúolos intra e extracitoplasmáticos. A camada córnea apresentou-se descontínua e formada apenas por algumas células queratinizadas. Essas alterações estão de acordo com as lesões observadas no epitélio ruminal de novilhos fistulados submetidos à sobrecarga alimentar com cereais (Ahrens, 1967).

A infusão intra-ruminal de lactato aumentou a quantidade de ribosomas livres e agrupados e causou degeneração de mitocôndrias nas células da camada basal. Hemidesmosomas e desmosomas foram pouco evidenciados, e a presença de membrana basal íntegra foi pouco freqüente. Células da camada espinhosa apresentaram núcleo com heterocromatina formando massas compactas. $O$ espaço intercelular mostrou-se bastante amplo, sugerindo retração celular e menor quantidade de desmosomas. As células da camada granulosa mostraram-se bastante vacuolizadas, contendo mitocôndrias em degeneração, pequenos grânulos limitados por membrana, algumas vesículas, sugerindo a presença de gotículas lipídicas entremeadas com grânulos de queratohialina e material fibrilar. As células queratinizadas mostraram-se elétron-densas, preenchidas com restos de organelas degeneradas associadas a material amorfofibrilar. $\mathrm{O}$ espaço intercelular apresentou-se bastante aumentado, contendo estruturas esféricas, sugerindo a presença de microrganismos, um indicador de dano na barreira física entre o conteúdo ruminal e a membrana basal (Fig. 4).

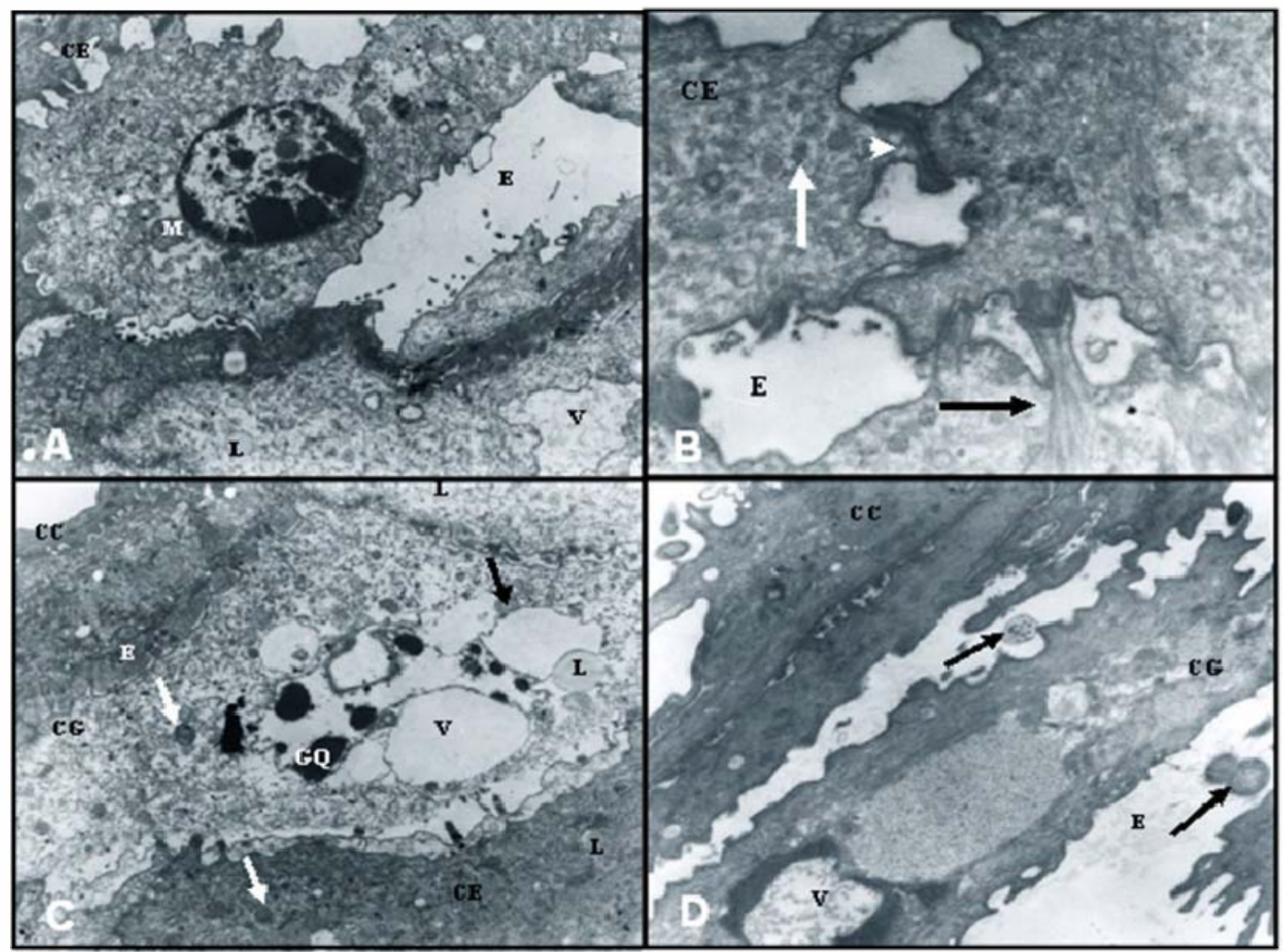

Figura 4. Micrografias eletrônicas do epitélio ruminal (lactato). A e B) Camada espinhosa (CE). Espaços claros (E) em áreas onde foram perdidos contatos intercelulares e desmosomas nas regiões de contatos dessas células (cabeça de seta branca). Filamentos inseridos na placa desmosômica (seta preta). Grânulos envoltos por membrana (seta branca). Grandes vacúolos (V) e gotículas lipídicas (L). 7.760X e 16.032X, respectivamente. C) Camadas espinhosa, granular (CG) e córnea (CC). Grânulos envoltos por membrana (seta branca) e grânulos de queratohialiuna (GQ). Mitocôndria em degeneração (seta preta). 7.760X. D) Camadas granular e córnea. Estruturas esféricas (seta) no espaço intercelular (E), sugerindo a presença de microrganismos ciliados intra-epiteliais. 12.880X 
A diminuição da atividade da bomba de íons $\mathrm{Na}^{+}-$ $\mathrm{K}^{+}$é seguida por um influxo de $\mathrm{Na}^{+}, \mathrm{Ca}^{+2}$ e água para dentro da célula e pela difusão de $\mathrm{K}^{+}$e $\mathrm{Mg}^{+2}$ para fora da célula (Jones et al., 2000). O lactato pode ter alterado o funcionamento da bomba de íons, necessário para a manutenção da pressão osmótica intracelular. Conseqüentemente, o aumento do conteúdo de água provocou dilatação de organelas, desarranjo da membrana celular e progressiva tumefação celular. Esse quadro foi classificado como ruminite química com degeneração hidrópica. Desde que maior atividade mitótica não tenha resultado em maiores dimensões papilares (Costa et al., 2008), é provável que o lactato tenha induzido proliferação celular, objetivando renovação celular e reestruturação do epitélio ruminal lesado.

Em dois dos quatro animais infundidos com butirato, foram visualizadas alterações muito graves no recesso e saco cego caudoventral do rúmen, caracterizadas por grandes áreas de erosão e presença de material amorfo-eosinofílico com desarranjo na arquitetura epitelial, diagnosticadas como ruminite química severa ulcerativa associada à necrose. Nos outros dois animais, as lesões foram classificadas como graves, assim como as lesões do saco cranial em todos os animais (Tab. 2 a 4 e Fig. 1).

A camada basal mostrou-se bastante desorganizada, não apresentando um padrão morfológico constante em sua estrutura, no tratamento B. Algumas células apresentaram núcleo vesiculoso e de contorno regular, enquanto outras apresentaram núcleo irregular e com heterocromatina dispersa. O espaço intercelular apresentou-se amplo, com presença de processos citoplasmáticos estirados e poucos desmosomas preservados. A membrana basal em algumas áreas mostrou-se ligeiramente tortuosa e descontínua. As células espinhosas localizadas próximas à camada granulosa mostraram-se achatadas e com núcleo contendo cromatina fragmentada. O citoplasma apresentou-se repleto de feixes filamentosos e com pequenos grânulos elétron-densos limitados por membrana dispostos na periferia da célula. Mitocôndrias em degeneração foram ocasionalmente observadas, com vacúolos vazios e outros cheios, sugerindo a presença de gotículas lipídicas. A membrana plasmática mostrou-se bastante espessada, e o espaço intercelular apresentou-se reduzido e contendo material granular fino. $\mathrm{Na}$ camada granulosa, foram observados grandes vacúolos intracitoplasmáticos associados a mitocôndrias em diversas fases de degeneração. Feixes filamentosos mostraram-se dispostos paralelamente à membrana plasmática, que se mostrou bastante espessada (Fig. 5). A infusão de butirato no rúmen induziu danos estruturais da parede ruminal caracterizada por ruminite química ulcerativa necrosante associada à hiperqueratose e paraqueratose ruminal.

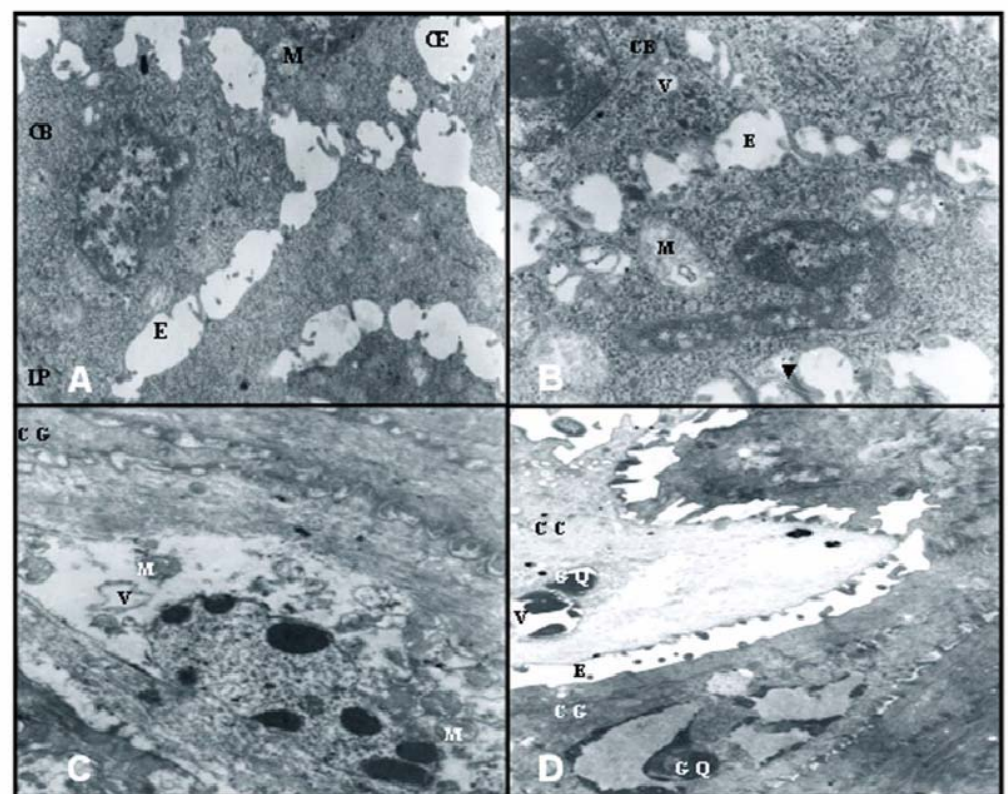

Figura 5. Micrografias eletrônicas do epitélio ruminal (butirato). A) Camadas basal (CB) e espinhosa (CE). Mitocôndrias (M) vacuolizadas. Espaço intercelular (E). Lâmina própria (LP). 7.760X. B) Camada espinhosa. Vacúolos (V). 4.048X. C) Camada granular (CG). 10.272X. D) Camadas granular e córnea (CC). Grânulos de queratohialina (GQ). 7.760X 


\section{CONCLUSÕES}

Dentre os AGV estudados, butirato e lactato foram os maiores indutores de alterações patológicas no epitélio ruminal. Os efeitos indireto e direto dos $\mathrm{AGV}$ sobre a morfologia dos tecidos epiteliais queratinizados não são idênticos. Biópsias tegumentares podem ter utilidade como indicadores de alterações morfológicas da mucosa ruminal.

\section{AGRADECIMENTOS}

Os autores agradecem à FAPEMIG (CAG 1269-97) e ao CNPq pelo apoio financeiro.

\section{REFERÊNCIAS BIBLIOGRÁFICAS}

AHRENS, F.A. Histamine, lactic acid, and hipertonicity as factors in the development of rumenitis in cattle. Am. J. Vet. Res., v.28, p.1335-1343, 1967.

BARKER, I.K.; VAN DREUMEL, A.A.; PALMER, N. The alimentary system. In: JUBB, K. V. F.; KENNEDY, P. C.; PALMER, N. (Eds). Pathology of domestic animals. 4.ed. San Diego: Academic, 1995. v.2.

BERNARDES, E.B.; COELHO, S.G.; CARVALHO, A.U. et al. Efeito de substituição do fenode Tifton 85 pelo carço de algodão como fonte de fibra na dieta de bezerros. Arq. Bras. Med. Vet. Zootec., v.59, p.955-964, 2007.

CALIARI, M.V. (Ed). Princípios de morfometria digital: KS300 para iniciantes. Belo Horizonte: UFMG, 1997. 149p.

CAMARGOS, E.R.S.; NETO, J.A.S. Técnicas rotineiras de processamento de material biológico em microscopia eletrônica de transmissão. Belo Horizonte: UFMG, 1995. $56 \mathrm{p}$.

COELHO, S.G. Ganho de peso e desenvolvimento do estômago de bezerros desaleitados aos trinta dias de idade e alimentados com concentrado e com ou sem feno. 1999. 123f. Tese (Doutorado) - Escola de Medicina Veterinária, Universidade federal de Minas Gerais, Belo Horizonte, MG.

COSTA, S.F.; PEREIRA, M.N.; MELO, L.Q. et al. Alterações morfológicas induzidas por butirato, propionato e lactato sobre a mucosa ruminal e a epiderme de bezerros. I. Aspectos histológicos. Arq. Bras. Med. Vet. Zootec., v.60, p.1-9, 2008.

CRICHLOW, E.C. Ruminal lactic acidosis: Forestomach epithelial receptor activation by undissociated volatile fatty acids and rumen fluids collected during loss of reticuloruminal motility. Res. Vet. Sci., v.45, p.364-368, 1988.

CRICHLOW, E.C.; CHAPLIN, R.K. Ruminal lactic acidosis: Relationship of fore stomach motility to no dissociated volatile fatty acids levels. Am. J. Vet. Res., v.46, p.1908$1911,1985$.

DELLMANN, H.D.; BROWN, E.M. Histologia veterinária. Rio de Janeiro: Guanabara Koogan, 1982. 397p.
GÁLFI, P.; GABEL, G.; MARTENS, H. Influence of intracellular matriz components on the growth and differentiation of ruminal epithelial cells in primary culture. Res. Vet. Sci., v.54, p.102-109, 1993.

HENDRY, K.A.K.; MacCALLUM, A.J.; KNIGHT, C.H. et al. Effect of endocrine and paracrine factors on protein synthesis and cell proliferation in bovine hoof tissue culture. J. Dairy Sci., v.66, p.23-33, 1999.

JENSEN, R.; FLINT, J.C.; UDALL, R.H. et al. Parakeratosis of the rumens of lambs fattened on the pelleted feed. Am. J. Vet. Res., v.15, p.202-216, 1954.

JONES, T.C.; HUNT, R.D.; KING, N.W. Patologia veterinária. 6.ed. São Paulo: Manole, 2000. 1415p.

KRAJCARSKI-HUNT, H.; PLAIZIER, J.C.; WALTON, J.P. et al. Short communication: effect of subacute ruminal acidosis on in situ fiber digestion in lactating dairy cows. $J$. Dairy Sci., v.85, p.570-573, 2002.

KREHBIEL，C.R.; HARMON，D.L.; SCHNIEDER，J.E. Effect of increasing ruminal butyrate on portal and hepatic nutrient flux in steers. J. Anim. Sci., v.70, p.904, 1992.

LUNA, L. G. Manual of histology staining methods of the Armed Forces Institute Pathology. 3.ed. New York: McGraw Hill, 1968. 258p.

McGAVIN, M.D.; MORRIL, J.L. Scanning electron microscopy of ruminal papillae in calves fed various amounts and forms of roughage. Am. J. Vet. Res., v.37, p.497-508, 1976.

PEREIRA, M.N.; GARRET, E.F.; OETZEL, G.R. et al. Partial replacement of forage with no forage fiber sources in lactating cow diets. I. Performance and health. J. Dairy Sci., v.82, p.2716-2730, 1999.

PERRIER, R.; FERCHAL, E.; DURIER, C. et al. Effect of undernutrition on the ability of the sheep rumen to absorv volatile fatty acids. Reprod. Nutr. Develop., v.34, p.341-347, 1994.

ROSS, R.L.; KITTS, W.D. Relations between posprandial plasma volatile fatty acids, glucose and insulin levels in sheep fed different feeds. J. Nutr., v.103, p.488-493, 1973.

SINGH, S.S.; MURRAY, R.D.; WARD, W.D. Histopathological and morphometric studies on the hooves of dairy and beef cattle in relation to overgrown sole and laminitis. J. Comp. Pathol., v.107, p.319-328, 1992.

STAIANO-COICO, L.; KHANDKE, K.; KRANE, J.F. et al. TGF-alpha and TGF-beta expression during sodium-Nbutyrate-induced differentiation of human keratinocytes: evidence for subpopulations-specific up-regulation of TGFbeta mRNA in suprabasal cells. Expl Cell Res., v.191, p.286291, 1990.

TAMATE, H.; KIKUCHI, T. Electron microscopy study on parakeratotic ruminal epithelium in beef cattle. Jpn. J. vet. Sci., v.40, p.21, 1978.

USER'S guide: statistics. 5.ed. Cary: SAS Institute, 1985. 1290 p.

VAIR, C.; WARD, G.M.; FRANDSON, R.D. et al. Influence of sodium salts of volatile fatty acids on rumen development in the young calf. J. Dairy Sci., v.43, p.890, 1960. 